\title{
Accreditation document tracking system using Scrum approach
}

\author{
Shanti Faridah Salleh, Hamimah Ujir, Rohana Sapawi, Hashimatul Fatma Hashim \\ Centre of Quality Assurance and Academic Development, Universiti Malaysia Sarawak (UNIMAS), Malaysia
}

\begin{tabular}{l} 
Article Info \\
\hline Article history: \\
Received Dec 3, 2019 \\
Revised Feb 20, 2020 \\
Accepted Feb 28, 2020 \\
\hline
\end{tabular}

\section{Keywords:}

Accreditation document

Management

Interface optimization

Tracking

Web-based system

\begin{abstract}
Document tracking which involves recording and monitoring the movement of documents has been a time-consuming task for staff. Dislocation and overlooking of the timeline have always been the problems in document control. An effective tool such as a web-based system is the easiest way to be implemented in the workplace. The Accreditation Document Tracking System (ADTS) is designed to monitor the movement and timeline of the document from a department to another department throughout the accreditation process efficiently. The main objective of this project is to develop a system that can track the location of a document and its status of submission at every stage. This advantageous system is developed through scrum approach, which is the most widespread agile methodology used in the industry. It offers flexibility and simplicity to the system developer in upgrading the system. Furthermore, the Unified Modelling Language (UML) is used to describe the interaction between user and proposed system. UML consists of three visual diagrams: (i) Use case diagram, (ii) activity diagram, and (iii) sequence diagram. By following each stage of the diagrams, the proposed system is able to be developed in order to achieve the objective of this project within within the university as well Malaysian Qualification Agency (MQA) and Ministry of Higher Education (MOHE).
\end{abstract}

This is an open access article under the CC BY-SA license.

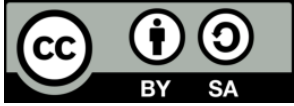

\section{Corresponding Author:}

Shanti Faridah Salleh,

Centre of Quality Assurance and Academic Development,

Universiti Malaysia Sarawak (UNIMAS),

Datuk Mohammad Musa Street, Kota Samarahan, Sarawak 94300, Malaysia.

Email: sshanti@unimas.my

\section{INTRODUCTION}

Accreditation is a voluntary process to assure the quality of education and academic development in higher education institutes. [1] has the opinion that improved academic quality is one of the positive aspects of internationalization of higher education. Not only that, [2] has mentioned that it is a way to reduce budget by maintaining education quality while serving various student populations. The effort of achieving better learning has becoming more emphasized when [3] has introduced the Progress Report on Generic Skills (PROG) which is an assessment tool to measure higher education students' generic skills in Japan. This is an effort in contributing good quality education for accreditation.

However, as indicated by [4], there is much difficulties when dealing with "quality" as different perceptions give a wide range of meanings which are based on the "understanding and objective of educational purposes". In conjunction with that, the quality of education is extremely hard to be defined easily. [5] also agreed that the quality of education relies more on the objective and level of education itself. In order to measure achievements and extents of quality for different levels of education, different quality standards should be applied. Therefore, [6] has defined that the quality of education can be achieved through developing quality assurance by implementing quality policy. 
The process of accreditation is often full of challenges as many people are involved and many tasks are to be done. Inefficient routing and tracking of reports as well as documents often occur due to lack of mechanism in internal and external escalation and lack of secure and centralized repository. A web-based system is recommended which can indicate the internal and external escalation as well as a secure and centralized repository for review and revision control.

A tracking system is the best way in solving the problems mentioned above. An Advanced Player Tracking System (APTS) is presented by [7] to reduce employees' workload by simplifying tedious tasks. This powerful system is welly developed and still has potential for upgrading. Therefore, this paper presents Accreditation Document Tracking System (ADTS) using scrum approach to assist those personnel in PJPA of UNIMAS to ensure the documentation flow is clear. This beneficial and advanced tool will be able to provide efficient routing and tracking for everyone who works for the department. All personnel will be able to access to all documents' statuses in a very short time. Scrum approach is the most widespread Agile methodology used in this high-tech industry and suitable to be developed for this ADTS.

\section{RESEARCH METHOD}

In Malaysia, quality assurance evaluation process in a higher education institution is primarily guided by some framework, standards and codes of practices such as The Code of Practice for Programme Accreditation (COPPA). [8] has conducted a study by adopting qualitative document analysis and interview techniques to investigate forty participants' awareness about the quality assurance practices in Ghanaian polytechnics. The study has revealed that the Polytechnics have made efforts for the development of internal quality assurance structures and institutional-wide quality assurance policies for programme accreditation. Among others, [8] has recommended that every higher education institution must select quality assurance practices which are relevant to its own context.

However, according to [9], the role of internal quality assurance in higher education is currently deep seated. A paper is produced to contribute a theoretical framework that supports professional development of internal quality assurance practitioners in higher education institutions which is synthesized from information available in literature. [10] has the same opinion as [8] where [10] has agreed that internal quality assurance systems of higher education institutions are self-regulated responsibilities which focus on continuous improvement of quality and achieving academic excellence. As mentioned by [10], the innovative Srinivas Institute of Management Studies (SIMS) has an Internal Quality Assurance cell (IQAC) by implementing academic auditing and adopting quality management strategies in all academic and administrative aspects. With an effective quality management and enhancement systems, SIMS reviews its teaching learning process, structure, methodologies of operations and learning outcomes at periodic intervals.

The development of web-based document tracking systems has been a new trend in document management or control. There are more and more of these systems created and developed in the workplace to replace the traditional document tracking system. In West Bengal of Eastern India, a workflow-based file tracking system (WFTS) is designed and applied for systematically maintain records of the movement of files in the offices of the government. The tracking of file is done through user defined parameters. Reports of file transaction information as well as daily and monthly file register are available in PDF Format. The highly secured database of WFTS is only accessible to authorized users only. It has an intra and inter-module easy navigation for its user-friendly design. Admin user can enter, edit and delete of sub-office master and official master for his or her own department. Other users only can see master data. However, super user and admin user cannot make any transaction of file. Only normal users can make any kind of transaction [11].

Not only that, [12] has explained about the development of a file tracking system for tertiary institution. It is a web-based application that can handle the making as well as the movement of the documents from one post to another post. Since it is a web-based system, user who use this system is able to do online tracking to locate the information of the document's location. The developer team decides to implement Unified Modelling Language (UML) into the system design. [13] defines UML as "A language for specifying, visualizing, construction, and documenting software system". The development of this system is quite similar to our proposed system development plan. Bootstrap is an open source toolkit for developing the system with HTML, CSS, and JS. But, on the functionality side, the system can only provide access to the secretary while our proposed system provide access to administrative as well as limited access to selected viewer from each faculty and department as well. There are several functionalities in this system that our proposed system is not capable of. One of them is sending message to other users and adding profile personal information to user account; which is irrelevant to our main objective [14].

However, iDMQA is another web-based system which adopts a scrum based online system. It is used to record document evidences and to keep them inside an integrated database. Additionally, users are able to do several tasks such as searching, adding and updating documents [14]. This system was developed 
to replace the traditional or conventional system. [15] also concludes by saying that using scrum allows their development team to unstiffen the scope that is inflexible in the beginning.

This system is developed through scrum approach, which is the most widespread Agile methodology used in the industry [16]. This method offers flexibility and simplicity to this system developer in upgrading the system when compared to the traditional software development. According to [17], traditional process is consuming more time as it is using a step by step approach in which the requirements, design, construction and testing phases are performed one after another. However, agile processes are slowly replacing the traditional approach towards late 90s. In recent years, most developers only prefer agile model for their software development as agile is a lightweight approach which adopts iterative software development methodology as shown in Figure 1 and Figure 2 shows iDMQA interface concept.

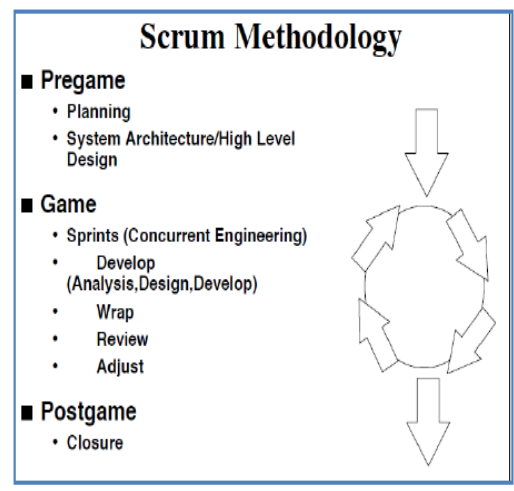

Figure 1. Phases in Scrum methodology [18]

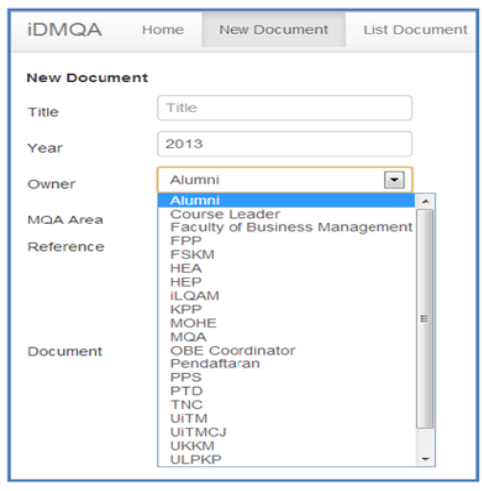

Figure 2. iDMQA interface concept [14]

The iDMQA consists of two type of users: users with broad IT understandings and users with limited IT understandings. The proposed system also has two types of user, but with completely different functionality compared with the types of users that have been implemented in iDMQA.

Among these, Enhanced Document Management System (EDMS) is also a web-based application system that is used specifically for document management. What is SME? According to [19], "SMEs are generally considered to be non-subsidiary, independent firms which employ less than a given number of employees". [20] states that it is difficult to find a software that is suitable for SME in term of affordability as well as features. Figure 3 is a client/server model that shows the flow of the architecture between central server and client machine.

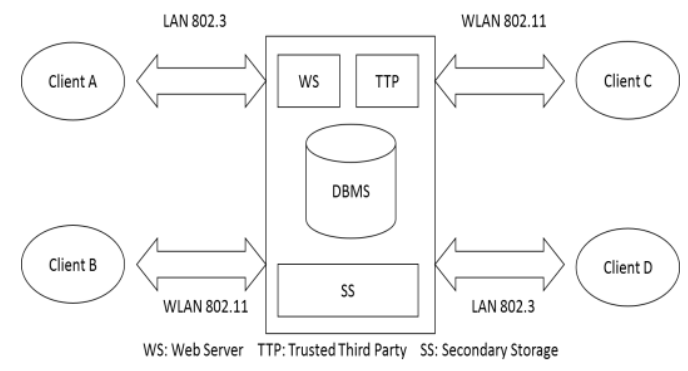

Figure 2. Architecture diagram of the EDMS

The objectives of this EDMS are: (i) to develop a web-based system that can record the movement of the document process; (ii) to develop a simple yet informative and constructive tracking view of the document in the form of table; and (iii) to develop an easy way for admin to update the document process status.

The system development is started with the modelling of proposed tracking system using the Unified Modelling Language (UML). It is a diagram-based modelling language and is used to describe the interaction between user and object [21]. As for [22], class diagram of UML has becoming a standard of 
the Information Technology (IT) in representing time varying data from the reality into objects. There are three models within UML: (i) Use Case Diagram; (ii) Activity Diagram; and (iii) Sequence diagram. The web system is developed using Hypertext Mark-up Language 5 (HTML5), Hypertext Pre-Processor (PHP), JavaScript (JS) and Cascading Style Sheet (CSS).

HTML5 and CSS are used to create and to style the user interface of this system. However, PHP is used to manage data transfer from the interface to the database of the system. PHP also has all the functions that are required such as updating and deleting the documents' status. According to [23], developers nowadays prefer PHP frameworks more than others due to the ability to create more complex, secure and complete web applications which is faster than those previous ones. Besides that, JS is a set of statements that performs a task or calculates a value. Not only that, MySQL is used to manage the database of the web system as it is one of the most popular tools that is fast, easy to use, and most importantly, it is free.

\subsection{UML diagram: Use case diagram}

Use case diagram is used to show the expected function that user can use on the proposed system. According to [24], it is a simple and yet powerful method for pinpointing the key system's features. This system has two type of users, administrators and viewers. Figure 4 shows the use case diagram for administrator and viewer for the system.

Both users have the same four functions, that are: (i) login, (ii) print document status, (iii) check file status, and (iv) logout. However, only administration user can manage the document by (i) create new status, and (ii) update current status.

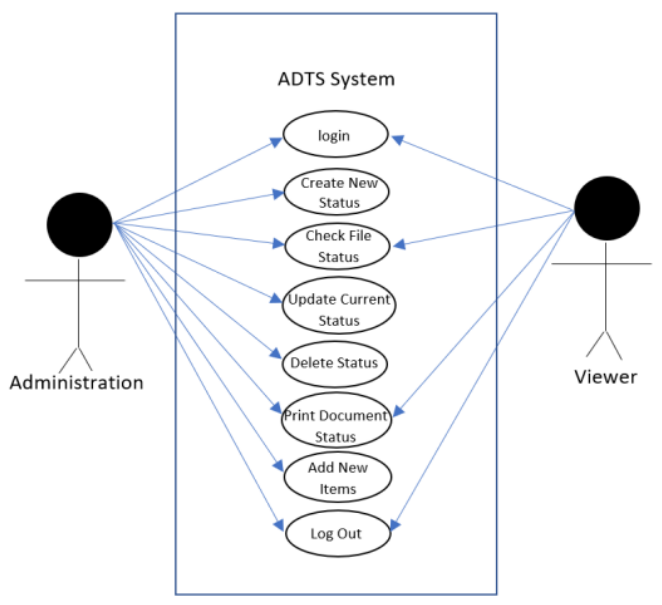

Figure 3. Use case diagram for admin and viewer

\subsection{UML diagram: Activity diagram}

Activity Diagram describes the flow of one entire process in the form of flowchart, but it is not a flowchart entirely. The flexibility of the proposed system can be determined by constructing the activity diagram as shown in Figure 5 [21].

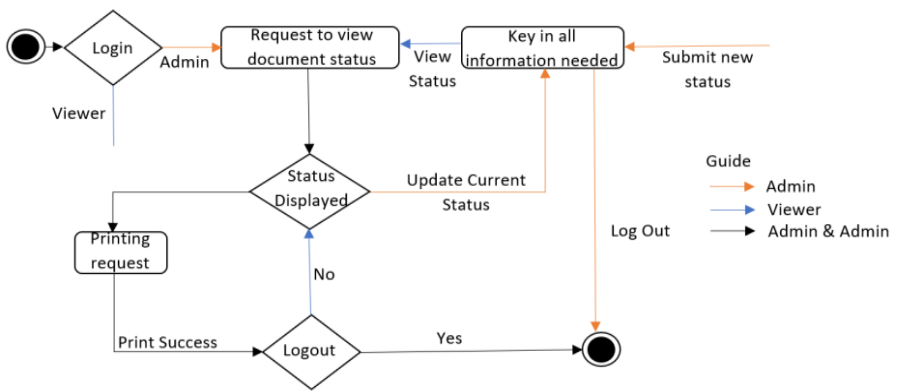

Figure 4. System's activity diagram 


\subsection{UML diagram: Sequence diagram.}

Sequence diagram is basically a diagram that explains the process which user will expect going through when using the proposed system. This includes the interaction that user needed to perform and several messages that user will receive from the system after completing the interaction. The following are the figures of the sequence diagram of admin and viewer [21].

Figure 6 shows the sequence diagram of user login. As usual, users will open the web browser to go to the system website. Then, users will be required to fill in their assigned username and password in order for them to $\log$ into the system. Figure 7 explains the viewing of document status. From the interface, users are able to go to document status list page by clicking the view document status option and to choose which program that the users want to view. This feature applies to both viewers and admin users. Viewers and admin users are also able to print the list of documents' statuses while viewing as shown in Figure 8. Figure 9 shows the sequences in the process of adding new document status into the system. From main menu, users can click on adding new status by choosing the option in the interface and fill in the form. This feature is available only for admin users. Figure 10 explains the update function of the system. This feature is almost similar to the adding of new document status. However, it requires users to view document status because the update option is available in the view document status interface. And again, this feature is available only for admin users. Figure 11 shows the sequences to log out from the system. This feature is available in all interface of the system. Users can just simply click on the logout option.

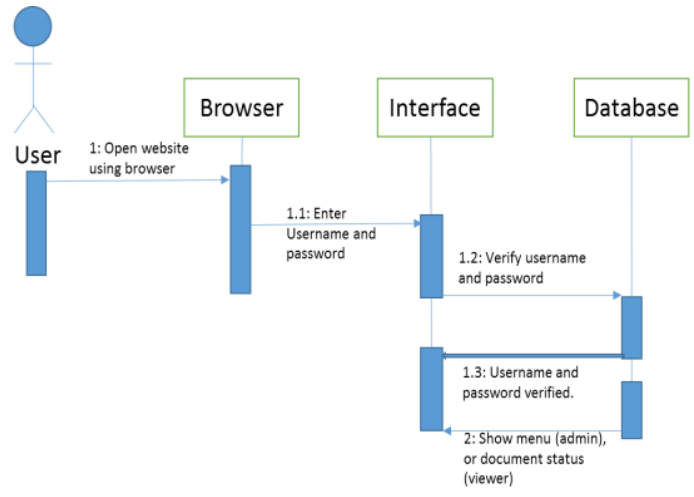

Figure 6. User login sequence diagram

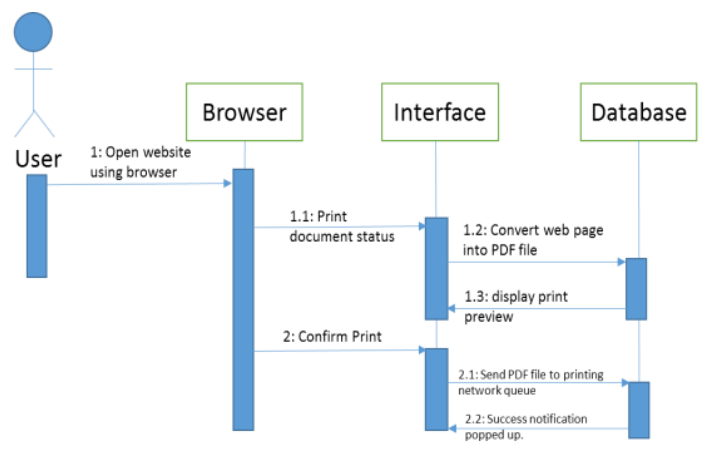

Figure 8. Print document status sequence diagram

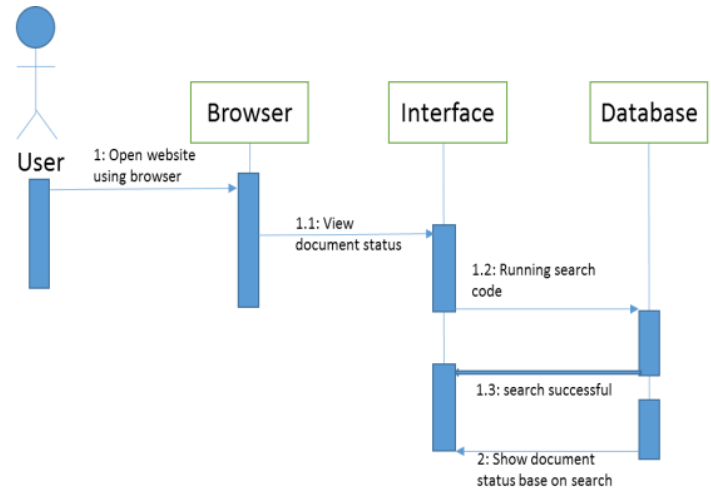

Figure 7. View document status sequence diagram

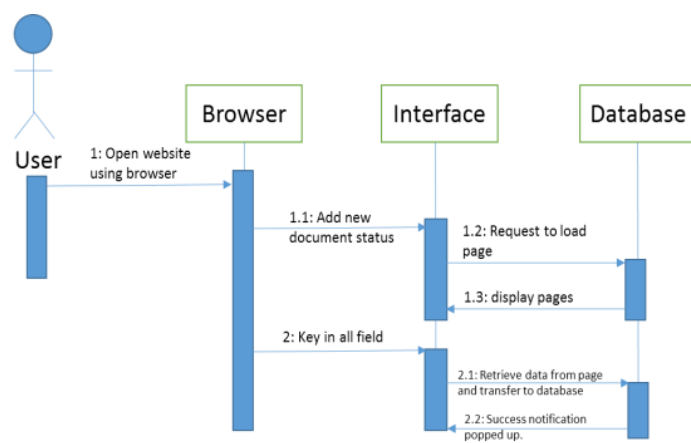

Figure 9. Add document status sequence diagram 


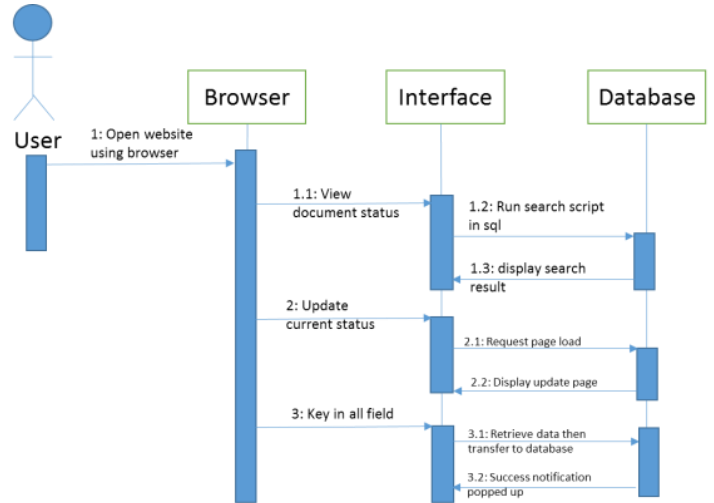

Figure 10. Update current document status sequence diagram

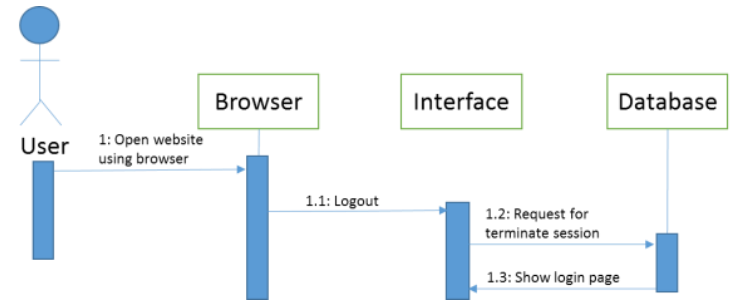

Figure 11. User logout sequence diagram

\section{RESULTS AND DISCUSSION}

Figure 12 is the interface of the login page. Users are able to enter the web system by providing their username and password. Figure 13 shows the admin form that is provided in the system. This is the entry of the new documents and to indicate whether the documents are for the submission to Malaysian Qualifications Agency (MQA) or Jabatan Pengajian Tinggi (JPT). Figure 14 shows the status list of documents. The reason for this is to simplify the information presentation, inserting multiple program status in one table will make the table look cluttered and convoluted. This table is sorted according to the latest date of updating the documents. As for the header in each column, 'Type of Document' represents the type of document that is escalating, 'Date of last updating' is for the latest date of updating the status of that particular document, 'Document location' represents the current location of the document, 'Status' describe whether the document has been sent to certain location, or to tell whether the department has received the document, and lastly 'Remarks' will give extra information about the document situation. Figure 15 above shows the numerical figures that are generated to indicate the number of document types and the number of documents which are in process as well as completed. Both functional and non-functional requirement was performed. The comparison between the proposed system and the existing systems that has been mentioned in literature review previously.

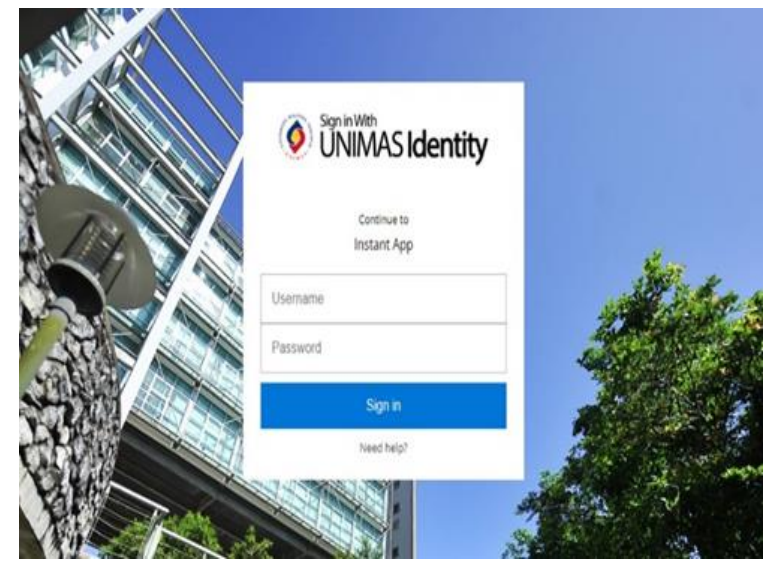

Figure 12. Login page for admin and viewer

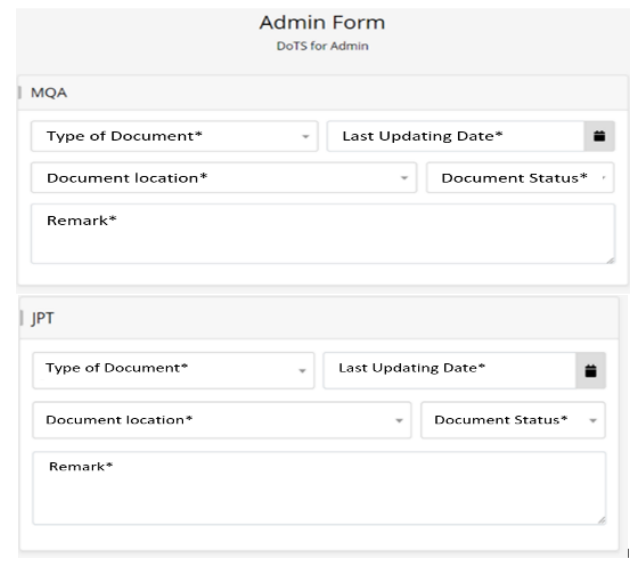

Figure 13. Admin Form 


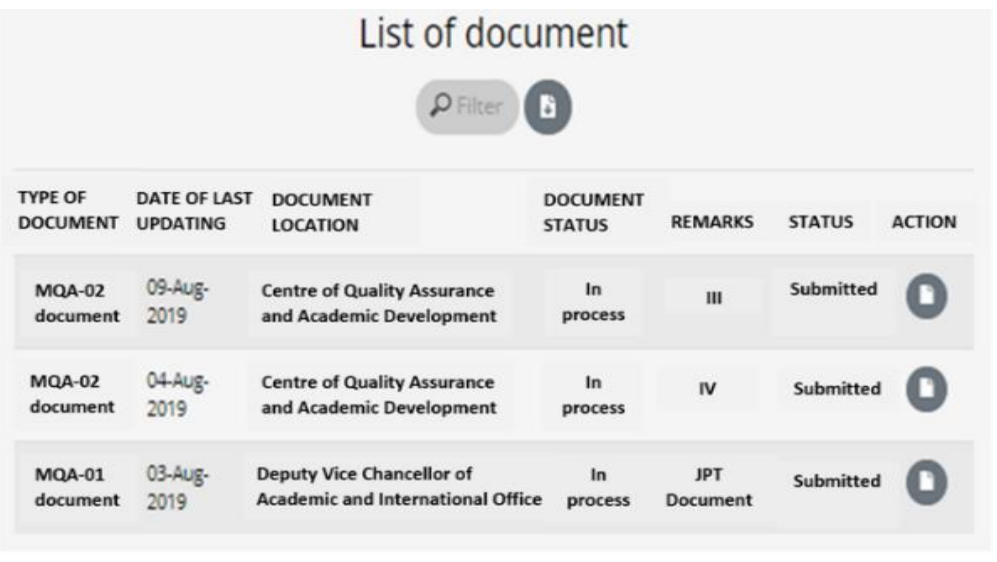

Figure 14. List of documents

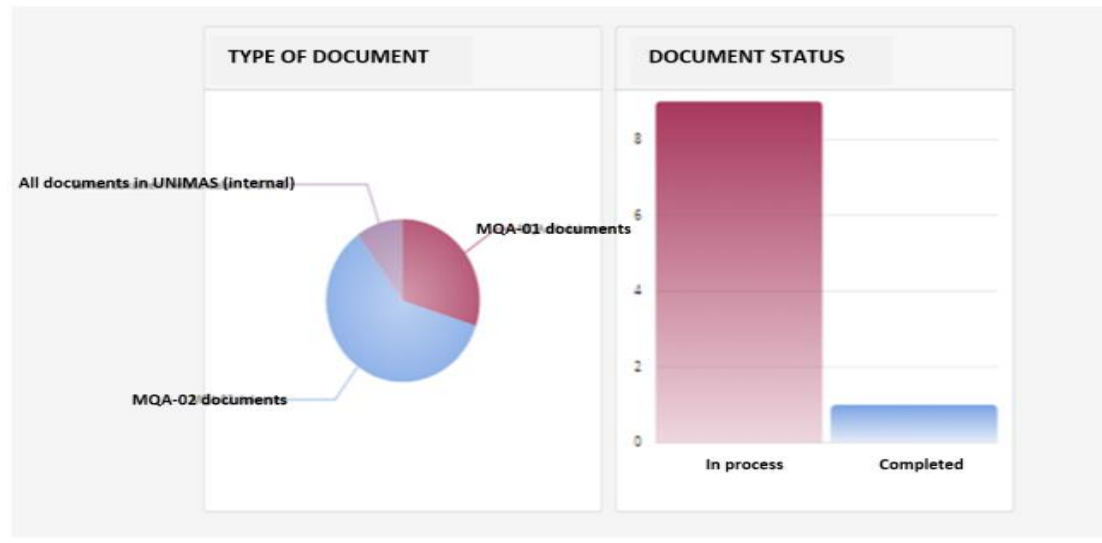

Figure 15. Numerical figures

\subsection{Functional testing}

According to [25], functional testing is the form of testing thru in contradiction of the business requirement of system or application. Interface Testing also applied during this stage, and based on the testing result, there are lots of area that need to be fix. It is not a system breaking problem, but the problem will ruin user experience when navigating the system.

\subsection{Non-functional testing}

According to [25], it is a type of testing that is done against the non-functional requirements. In this testing phase, we have covered the (i) Availability Testing; (ii) Compatibility Testing; and (iii) Load Testing.

The availability testing was carried out to discover whether the web host is available for 24 hours a day. Since the proposed system using free web host, there's a time when the system can't be open because of the server is down. As for compatibility testing, the system has been tested using several types of browser, and system is compatible to most of the browser that is used for this testing. Lastly, we perform load testing, the purpose of this test is to see whether the system can load faster. The result of the test is not that convincing. Even though we are using high speed internet, the loading speed can be slow if the server of the web host is not stable. There are three (3) other systems being compared with the proposed system, they are:

a. "Development of a File Tracking System for Tertiary Institution" by N. A. Omoregbe, et al.

b. "An Integrated Document Management System for Managing Self Programme Accreditation Using Scrum Approach” by R. Mokhtar et al.

c. "An Enhanced Document Management System for SME” by M. Agarkar et al.

Table 1 shows the comparison result between proposed system and the other three systems that have been discussed in literature review. In the table, the systems are compared whether they are 'Web Based' system, 'Can show current status with previous status', has 'printing function', is it 'platform friendly', and 
lastly the systems' 'cost of implementation is reasonable'. Among all, the proposed system - ADTS has all the functions mentioned in Table 1. Therefore, this ADTS can be a very effective tool to be used throughout the accreditation process.

Table 1. Comparison between systems.

\begin{tabular}{lcccc}
\hline Function & \multicolumn{3}{c}{ Systems } \\
& Proposed system & (a) & (b) & (c) \\
\hline Web Based & $\checkmark$ & $\checkmark$ & X & $\checkmark$ \\
Show current status with & $\checkmark$ & X & X & X \\
previous status & & & & \\
Printing function & $\checkmark$ & X & X & X \\
Platform friendly & $\checkmark$ & $\checkmark$ & $\checkmark$ & $\checkmark$ \\
$\begin{array}{l}\text { Implementation cost is } \\
\text { reasonable }\end{array}$ & $\checkmark$ & $\checkmark$ & $\checkmark$ & $\checkmark$ \\
\hline
\end{tabular}

\section{CONCLUSION}

This paper has discussed the scheme and execution of the web-based accreditation document tracking system. The main objective of this project is achieved when system is designed and developed mainly to track accreditation across the process in the different faculties within University as well Malaysian Qualification Agency (MQA) and Ministry of Higher Education (MOHE).

\section{ACKNOWLEDGEMENTS}

Authors would like to thank UNIMAS for funding through top down grant that supported the study of 'UNIMAS readiness and challenges in implementing self accreditation of its Academic Programmes'. Much appreciation goes to my colleagues for their persistence and involvement in the succession of this project through to the end. Their inspiration gave me the motivation to keep going with the development of this project until this tool is completely developed.

\section{REFERENCES}

[1] T. Jibeen, M.A. Khan, "Internationalizaton of higher education: Potential benefits and costs," International Journal of Evaluation and Research in Education (IJERE), vol. 4, no. 4, pp. 196-199, Dec 2015.

[2] R.W. Elliott, "Understanding faculty engagement in assessment through feedback and dialogues: A mixed methods approach," International Journal of Evaluation and Research in Education (IJERE), vol. 7, no. 3, pp. 167-175, Sep 2018.

[3] H. Ito, "Assessing an assessment tool of higher education: Progress report on generic skills (PROG) in Japan," International Journal of Evaluation and Research in Education (IJERE), vol. 3, no. 1, pp. 1-10, Mar 2014.

[4] K. H. Allehaibi, N. N. Albaqami, "A unified quality control model for e-learning systems," IJECE, vol. 7, no. 3, pp. 1355-1366, Jun 2017.

[5] Nabil Moussa and Sandra Moussa, "Quality assurance of e-learning in developing countries. Nonlinear analysis: Theory, methods \& applications," vol. 71, no. 12, pp. e32-e32, Dec 2009. ISSN 0362-526X, [Online] Available: http://www.sciencedirect.com/science/article/B6V0Y-2TP29K2-3/2/a9d3277e60036b50f0a8b622c5d70738

[6] Rose, Kenneth H, "Project quality management: Why, what and how. fort lauderdale", Florida: J. Ross Publishing, pp. 41, ISBN 1-932159-48-7, Jul 2005.

[7] A. “Skerbinek, B. Vlaovi`c, “Advanced player tracking system,” IJECE, vol. 9, no. 2, pp. 1418-1425, Apr 2019.

[8] O.A. Samuel, "Internal quality assurance in higher education institutions: The case of some selected Ghanaian Polytechnics," European Journal of Research in Social Sciences, vol. 4, no. 8, ISSN 2056-5429, 2016.

[9] M.J. Raphael, K. Reckson, "A competency framework for internal quality assurance in higher education," Int. J. Management in Education, vol. 13, no. 2, 2019.

[10] P.S. Aithal, "Internal quality assurance cell and its contribution to quality improvement in higher education institutions: A case of Sims," Ge-International Journal Of Management Research, vol. 3, no. 5, May 2015.

[11] National Informatics Centre, "User manual for systematically maintain records of the movement of files in the offices of the government of West Bengal," Department of Information Technology.

[12] N. A. Omoregbe, et.al. Edeh, "Development of a file tracking system for Tertiary institution," in Proceeding of EDULEARN14 Conference, Barcelona, Spain., 2014.

[13] P. Fitsilis, V. C. Gerogiannis and L. Anthopoulos, "Role of unified modelling language in software development in Greece - results from an exploratory study," IET Journal, vol. 8, no. 4, pp. 143-153, 2013.

[14] R. Mokhtar, et al, "An integrated document management system for managing self programme accreditation using Scrum approach," Technology Management and Emerging Technologies (ISTMET), 2014 International Symposium on, Bandung, Indonesia, 2014.

Int. J. Eval. \& Res. Educ. Vol. 9, No. 1, March 2020: 153 - 161 
[15] J. Patton, "Unfixing the fixed scope project: using agile methodologies to create flexibility in project scope," in Proceedings of the Agile Development Conference, Salt Lake City, UT, 2003.

[16] S. Anwar, Y. H. Motla, Y. Siddiq, S. Asghar, M. S. Hassan and Z. I. Khan, "User-centered design practices in scrum development process: A distinctive advantage?," in 17th International Multi-Topic Conference (INMIC), Karachi, Pakistan, 2014.

[17] B. Prakash, V. Viswanathan, "A survey on software estimation techniques in traditional and agile development models," IJEECS, vol. 7, no. 3, pp. 867-876, Sep 2017.

[18] K. Schwaber, "SCRUM development process," J. Sutherland, C. Casanave, J. Miller, P. Patel \& G. Hollowell Business Object Design and Implementation, London, Springer, pp. 117-134, 1997.

[19] OECD, "Outlook for SME performance and policies: What are SMEs?," in OECD Small And Medium Enterprise Outlook, Paris, OECD Publication, pp. 7, 2012.

[20] M. Agarkar, et al., "An enhanced document management system for SME," in IEEE Eighth World Congress on Services, Honolulu, HI, 2012.

[21] J. S. Valacich, J. F. George and J. A. Hoffer, Essentials of systems analysis and design, 5th ed.

[22] A.E.H. Soumiya, B. Mohamad, "Converting UML class diagrams into temporal object relational database," IJECE, vol. 7, no. 6, pp. 2823-2832, Oct 2017.

[23] K. Benmoussa, M. Laaziri, S. Khoulji, M. L. Kerkeb, A.E. Yamami, "A new model for the selection of web development frameworks: Application to PHP frameworks," IJECE, vol. 9, no. 1, pp. 695-703, Feb 2019.

[24] J. Marchewka, Information technology project management: Providing measurable organizational value, Hoboken, NJ: Wiley, 2002.

[25] S. Casteleyn, F. Daniel, P. Dolog and M. Matera, "Engineering Web Applications," Berlin/Heidelberg, Germany: Springer Science \& Business Media, 2009. 